\title{
Comparison of the obtained results of 3D versus 2D echocardiography regarding the function of the left atrium in the population without cardiovascular disease
}

\author{
Fatmir Ferati*, \\ Mentor Karemani², \\ Nexhbedin Karemani', \\ Neset Uzairi', \\ Anida Ferati ${ }^{3}$
}

'Clinical Hospital Tetovo, State University of Tetovo, Tetovo, Macedonia

${ }^{2}$ Medikus, Tetovo, Macedonia ${ }^{3}$ Medartis, Tetovo, Macedonia

RECEIVED:

September 10, 2014
KEYWORDS: left atrium, left atrial ejection fraction, global longitudinal strain, volume. CITATION: Cardiol Croat. 2014;9(9-10):376.

*ADDRESS FOR CORRESPONDENCE: Spitali Klinik Tetovë, Memet Pashe Derala bb, 1200 Tetovë, Republika Makedonija. / Phone: +389-70-224138 / E-mail: fatmir_ferati@yahoo.com

|l||||||||||||||||||||||||||||||||||||||||||||||||||||||||||||||||||||||||||||||||||||||||||||||||||||||||||||||||||||||||||||||

The objective of the study is the analysis of the left atrium (LA), comparison of the results in the function of LA during 2D vs 3D echocardiography, verification of the eventual changes and to determine the minimal values (cut off values) of the normal function of the LA in normal population.

In the study have analyzed the ejection fraction (EF) of the left ventricular (LV), EF of the left atrium (LA), LA volume as well as the global longitudinal strain (GLS) of the LA. As reference values have been used the values proposed in the function of the left atrium: 1. Endsystolic volume of the left atrium $<34 \mathrm{ml} / \mathrm{m}^{2} ; 2$. EF of the LA $>41 \%$; 3 . Global longitudinal strain of the $\mathrm{LV}$ in $2 \mathrm{D}>36.2 \%$

We have analyzed 42 persons (22 female and 20 male patients) without cardiac disease, with the average age of $47 \mathrm{y}$. (+/- 8). All of them where analyzed with Philips IE 33x Matrix (Vision 2012), with the scanhead X5. Collected data's where analysed with Tomtec.gmbh, with software for 2D speckle tracking (cardiac performance analysis) and with software for 3D strain (4D LV analysis vers. 3.1.).

Based on the results, we can draw the following conclusions: 1. EF value of the LA in 2D echocardiography in people with no signs of cardiovascular disease in 2D as well as 3D echocardiography, is above 41\%; 2 . The LA volume value in 2D echocardiography is $34.09 \mathrm{ml} / \mathrm{m}^{2}$ and is the range of proposed normal values in the literature; 3 . Cutt up value for 2D GLS of LA in our study is $38.7 \%$, and corresponds with the proposed GLS values of $36.2 \%$ in literature; 4 . Cut off value in the normal functioning of LA in 3D GLS in our study is 21.5\%. Starting from this the GLS value of LA in 3D, should be above 21\%, for persons that have a normal heart functioning; 5 . This differs from the values of 2D GLS of LA from $36.2 \%$ which is proposed for the normal function of LA which is analyzed with the 2D method.

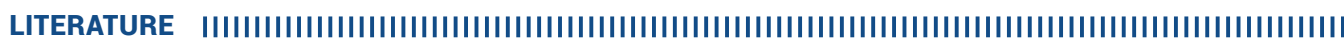

1. Wang Z, Tan H, Zhong M, Jiang $G$, Zhang $Y$, Zhang W. Strain rate imaging for noninvasive functional quantification of the left atrium in hypertensive patients with paroxysmal atrial fibrillation. Cardiology. 2008;109(1):15-24.

2. Pagel PS, Kehl F, Gare M, Hettrick DA, Kersten JR, Warltier DC. Mechanical function of the left atrium: new insights based on analysis of pressure-volume relations and Doppler echocardiography. Anesthesiology. 2003;98(4):975-94.

3. Lang RM, Bierig M, Devereux RB, et al; Chamber Quantification Writing Group; American Society of Echocardiography's Guidelines and Standards Committee; European Association of Echocardiography. Recommendations for chamber quantification: a report from the American Society of Echocardiography's Guidelines and Standards Committee and the Chamber Quantification Writing Group, developed in conjunction with the European Association of Echocardiography, a branch of the European Society of Cardiology. J Am Soc Echocardiogr. 2005;18(12):1440-63. 